\title{
Human health and occupational exposure to pesticides among smallholder farmers in cotton zones of Côte d'Ivoire
}

\author{
Oluyede Clifford Ajayi ${ }^{*}$, Festus Kehinde Akinnifesi, Gudeta Sileshi
}

World Agroforestry Centre, Nairobi, Kenya; ${ }^{*}$ Corresponding Author: Ajayi@gmx.net

Received 14 June 2011; revised 13 July 2011; accepted 21 July 2011.

\begin{abstract}
While precautionary efforts are being made to minimize human health problems associated with agricultural pesticides, the continued occurrence of occupational poisoning from these chemicals raises major concerns among stakeholders. Information gap on human health problems associated with pesticides poses major obstacles to making informed policy decisions, particularly in developing countries where most of the poisonings occurs. In this study, we identified acute human health symptoms associated with pesticide use in cotton zone of Côte d'Ivoire and, documented the response of rural households to the symptoms. The results show that cotton farmers in Cote d'Ivoire suffer from different occupational health hazards from exposure to agricultural pesticides. Key health symptoms reported by pesticide applicators are headache, rheum, cough, skin rash and sneezing. Pesticide applicators reported four times higher symptoms of ill health than other household members who do not normally handle pesticides. Although, households recognized pesticides as an important cause of ill health, some of the symptoms have been accepted as norm by individuals who apply pesticides. Official data on pesticide poisoning in the country is most likely to be seriously under-estimated as applicators visited formal health centers for medical assistance in only $2 \%$ of poisoning cases reported. There is a high likelihood that households in the study area under-estimated pesticide-related health costs in making farm production decision-making. Approaches to use economic instruments for reliable monitoring and reporting procedures to formulate appropriate policies and regulations to minimize exposure to pesti-
\end{abstract}

cides are recommended. Health planners and policy makers should aim at reducing the risks posed by pesticide to farm households by, improving awareness of farmers; promote complementary approach (e.g. Integrated Pest Management) and, use of economic instruments and improved surveillance to bridge the gap in the documentation of pesticide poisoning cases among farmers.

Keywords: Occupational Health; Health Policy; Pesticide Externality; Agriculture-Health Linkage; Consumer Protection

\section{INTRODUCTION}

Pesticides play an important role in minimizing potential losses of agricultural production and livestock. However, the chemicals have the characteristics to produce joint outputs because they usually generate the intended outputs (saving crops from damage) and, simultaneously producing unintended outcome such as negative impacts on the environment and human health. Globally, pesticide poisonings in the agricultural sector accounts for between 250,000 to 370,000 human deaths annually [1], most of these deaths occurred in developing countries. The cost of public health impact of pesticide use in the USA is estimated at US\$ 1.1 billion annually [2], although figures for developing countries is much lower [3]. While various efforts have been made to minimize pesticide-related health problems including changing from more toxic chemicals to less toxic ones (e.g. from organochlorines and organophosphates pesticides to pyrethroids), and warning labels to communicate risk information to users [4,5], increases in the quantity of pesticides and exposure to the chemicals continue to fuel concerns about human health problems associated with pesticides. Most of the environmental impacts assessment on pesticides was conducted in developed countries and, only few empirical studies have 
assessed non-intended negative environmental effects of pesticides in Africa. Documented cases of environmental impacts in Africa focused on pesticide residues and the contamination of water $[6,7]$ and degradation of biological capital of ecosystems [8].

The effects of pesticides on human health in the developing regions have been eliciting much interest because most of the pesticide poisoning cases occur in that part of the world. In Nicaragua, an extremely high risk of acute pesticide poisoning estimated at 66,000 cases annually, most of which occur particularly among agricultural workers in rural areas has been reported [9]. In Nepal, individuals who applied pesticides had signifycantly higher probability of falling sick from pesticiderelated symptoms than members of the same household who were not exposed to chemicals [3]. Other empirical field studies of the human health implications of pesticides among agricultural workers and households have been documented in the Philippines [10] and Ecuador $[11,12]$. In Africa, field studies show that pesticides cause changes in acetylcholinesterase inhibition and increased health symptoms among agricultural workers in Kenya [13]. The chemicals have been associated with significantly impaired neurobehavioral performance among individuals who apply pesticides in the cotton fields in Egypt [14]. Recent toxicological studies in South Africa reported that exposure of children to pesticides and, poisoning from the chemicals has emerged as an increasingly important problem in the country [15]. Information on human health implications of pesticides is therefore essential to formulate appropriate policies for reducing occupational risks from pesticide poisoning among farm population [16].

The objectives of this study is to identify the human health impacts of the use of pesticides on farm households in the cotton farming systems of Côte d'Ivoire using empirical field data and laboratory analyses. Specifically, the study answers the following questions: "Are there human health problems associated with the use of pesticides in agricultural households?” If yes, "what are they?"; "How do farmers respond to the symptoms under actual level of attitudes and information on pesticide-related human health symptoms?”

\section{MATERIAL AND METHODS}

\subsection{Description of Study Area and Sampling Technique}

The study was undertaken in northern Côte d'Ivoire situated between latitude $8^{\circ}$ and $9^{\circ}$ North and Longitude $5^{\circ}$ and $6^{\circ}$ West. In addition to the regional capital town of Korhogo, the major towns within the area of study are Ferkéssédougou, Tafiré, Niakaramadougou and Katiola.
The area is predominantly populated by the native Senoufos, although there are few pockets of other immigrants such as Peulhs, who are mainly livestock farmers and Dioulas who are essentially traders. The agricultural economy of the study area is dominated by cotton and cereal production. Although the quantity of pesticides use in African agriculture is lower than global figures, cotton is one of the few crops where large quantities of pesticides are used in the continent. The use of pesticides in Côte d'Ivoire is particularly reinforced by historic and several government policies that have promoted cotton production and pesticide use. An example of such policies is the distribution of free pesticides to cotton farmers on a standard dose for every hectare of cotton they cultivated. The details of these policies and other institutional supports to promote cotton and pesticide use in the study area have been documented $[17,18]$ using an economic framework developed by Waibel to analyze crop protection policies and how such policies contribute to promoting the use of pesticides in developing countries [19]. Two sites were selected from the study area: $\mathrm{Ka}$ tiola is located in the southern part of the main cotton producing zones and historically, pesticides have been used for relatively shorter period (less than two decades) in this site. Korhogo is located in the core cotton zone in the northern part of the country and, intense use of pesticides has taken place in the site for longer period spanning about four decades. Using stratified random sampling technique, two villages were selected from Katiola and three villages from Korhogo. A representative random sample of 33 households was selected in each village, i.e. a total sample size of 132 households. The details on the selection of households are documented elsewhere [4].

\subsection{Data Collection}

Three sets of information that were identified to be important for the objectives of the study were collected using different approaches.

\subsubsection{Field Monitoring of Pesticide Application}

We collected information on the type of pesticides applied, quantity applied, duration of application (proxy for exposure) and protective clothing worn by pesticide applicators. Other data collected include the method of transportation of chemicals from households to farms, precautionary measures taken against wind, dosage and method of mixing pesticides, type and condition of equipment used. The information was obtained through post-application interviews conducted by the trained resident field technician and assistants immediately (the same evening or the next day) that cotton farmers sprayed their fields. In some cases, the field research assis- 
tants followed farmers to the field and collected the same information through direct observation. The data collection process for this set of information was carried out each time that farmers sprayed their fields.

\subsubsection{Household Health Monitoring Survey}

After each pesticide application, the specific person(s) within the household who carried out pesticide application in cotton fields (usually the male head of household) was interviewed to collect information whether he experienced any acute health symptoms associated with pesticide application. In this study, an acute health symptom that is reported by a pesticide applicator is associated with pesticide application only if the victim did not suffer from the symptom before applying, but it began only during or within 24 hours after applying pesticides. Similar time limit has been used in other studies [20]. It is possible that the time limit may underestimate health costs since some symptoms take much longer to appear, but our focus is on acute symptoms only. We wanted to avoid the possibility of including other symptoms that are not related to pesticides. Self-reporting of health symptoms is an approach commonly used by researchers to estimate risks of acute poisonings from agricultural pesticides $[3,9,20]$.

\subsubsection{Residue Analysis}

Pesticide residue analysis was carried out to investigate a possible relationship between the health symptoms that were reported by applicators and, level of chemical exposure. In one of the field application of chemicals, we superimposed two pieces of new clothing material $(20 \mathrm{~m} \times 20 \mathrm{~m})$ each on pesticide applicators a few minutes before they began spraying operation. The pieces of cloth were collected at the end of spraying operation, wrapped in aluminum foils and taken to the laboratory for residue analysis. The pesticide deposits in the tissue materials were extracted and analyzed in an eco-toxicological laboratory located in Côte d'Ivoire. The results of the extracted residues were reported in micrograms $(\mu \mathrm{g})$ of active ingredient per $\mathrm{cm}^{2}$ of body surface. It is expected that the quantity of insecticides that would normally have fallen on applicators during spraying are absorbed by the cloth tissues.

\section{RESULTS}

\subsection{Health Symptoms Associated with Pesticide Application}

Pesticide applicators reported health symptoms once for every five times (20\%) that they carried out spraying operations. These were the symptoms that began during or within 24 hours after spraying operation. Applicators mentioned that "nothing happened" ('rien à signaler') during the remaining $80 \%$ of the times that they carried out pesticide application, i.e. they said they did not encounter extraordinary health problems that are beyond normal. There is a wide difference in the behavior of pesticide applicators across the two study sites. In Korhogo site that has a longer history of pesticide use, applicators reported health symptoms and seek attention in only $8 \%$ of the times that they apply pesticides. This figure contrasts with $37 \%$ in Katiola site where pesticides use began at a more recent period. In both regions, the symptoms reported were those applicators perceived to be the severe cases. The results compare with similar study in Kenya where $10 \%$ of the individuals that are exposed to pesticides experienced health symptoms during spraying operations and, a quarter did so much later after applying pesticides [13].

Several types of symptoms were mentioned by applicators who reported one symptom or the other. The five most economically important among these are headache, rheum, cough, skin rash and sneezing, in decreasing order of occurrence (Table 1).

These five symptoms alone accounted for $84 \%$ of all the symptoms reported. In Katiola, a wider range and higher number of symptoms were reported. These key symptoms are cough (24\%), headache (19\%), Sneezing (16\%), Rheum (15\%) and skin rash (9\%). In contrast, there were fewer number of symptoms reported in Korhogo as three symptoms dominate. The three symptoms which together account for $85 \%$ of all the symptoms reported

Table 1. Key health symptoms reported by pesticide applicators.

\begin{tabular}{cc}
$\begin{array}{c}\text { Type of } \\
\text { symptom }\end{array}$ & $\begin{array}{r}\text { Frequency of report of specific symptom relative to the } \\
\text { total number of symptoms reported (\%) } \\
\text { (\# of households }=127)^{1}\end{array}$ \\
\hline Headache & 25 \\
Rhume & 18 \\
Cough & 17 \\
Skin rash & 13 \\
Sneezing & 11 \\
Other & 16 \\
symptoms & 100 \\
Total &
\end{tabular}

Note: Figures are based on those who reported health symptoms only; ${ }^{1}$ Five farmers in Katiola site did not have complete health information and were dropped from the computation of this table. 
in the site are headache (38\%), skin rash (24\%) and rheum (23\%). Pesticide applicators treated almost all (98\%) the reported symptoms using homegrown methods or through purchase of drugs across-the-counter within or around the villages. Only in $2.2 \%$ of the cases (1.5\% in Korhogo site and $2.4 \%$ in Katiola site) did pesticide applicators visit official health centers for medical assistance.

The results of the weekly household health monitoring data provide additional insight into the occurrence of health symptoms between pesticide applicators and nonapplicators within the same household. Occurrence of all types of symptoms (i.e., whether associated with pesticides or not) that were reported by all household members shows that pesticide applicators had four times greater risk to fall sick (report an illness) than other members of the household (non-applicators) with whom they share similar socio-economic and livelihood conditions. Pesticide applicators constituted $17 \%$ of the entire household population, but the illnesses that they reported accounted for $45 \%$ of all the illnesses (morbidity) reported by members of the households. Similar studies in cotton fields in Egypt revealed that after controlling for age and education, field and laboratory tests show that pesticide applicators (both adults and children) performed significantly worse on the majority of neurobehavioral tests compared with the "controls" who are those not working in agriculture [14]. In Nepal, the cost of health care is reported to be eight times higher for individuals who spray pesticides than others in the same household who are not directly exposed to chemicals [3].

\subsection{Laboratory Tests of Pesticide Exposure among Pesticide Applicators}

Given that the symptoms discussed above were based on reporting by farmers, we analysed pesticide residues on the clothing imposed on pesticide applicators to provide some insights into whether the health symptoms mentioned above are indeed linked to pesticide exposure or not. The quantity of pesticide residues that was extracted from the cloth tissue that was imposed on pesticides applicators is presented (Table 2).

Based on the laboratory residue analysis, the total quantity of active ingredients residues which fell on the applicant's body during the spraying season is estimated at $202 \mu \mathrm{g}$ for every $\mathrm{cm}^{2}$ of the applicant's body in Korhogo site in contrast with $91 \mu \mathrm{g}$ in Katiola. This is equivalent to $2.02 \times 10^{6} \mu \mathrm{g}$ per $100 \mathrm{~cm}^{2}$ in Korhogo and $9.06 \times 10^{5} \mu$ g per $100 \mathrm{~cm}^{2}$ in Katiola site. The results imply that pesticide applicators in cotton fields of Korhogo site face two times higher risk of direct exposure to pesticides than their counterparts in Katiola site. The differences in exposure risk is explained by three related
Table 2. Estimated quantity of pesticide residues ( $\mu$ g of active ingredient) falling on applicators' body throughout the pesticide spraying season.

\begin{tabular}{cccc}
\hline Description of residue measured & $\begin{array}{c}\text { Korhogo } \\
\text { site }(\mathrm{n}=35)\end{array}$ & $\begin{array}{c}\text { Katiola } \\
\text { site }(\mathrm{n}=34)\end{array}$ & $\operatorname{Pr}>\mathrm{T}$ \\
\hline Extracted residue per $1 \times 1 \mathrm{~cm}$ area & 202 & 91 & 0.1950 \\
& & & \\
$\begin{array}{c}\text { Quantity of pesticide residue per } \\
100 \times 100 \text { cm area of cloth tissue } \\
\text { (extrapolated) }\end{array}$ & $2.02 \times 10^{6}$ & $9.06 \times 10^{5}$ & 0.1950 \\
$\begin{array}{c}\text { Quantity of pesticide residue per } \\
150 \times 150 \text { cm area of cloth tissue } \\
\text { (extrapolated) }\end{array}$ & $4.54 \times 10^{6}$ & $2.04 \times 10^{6}$ & 0.1950 \\
\hline
\end{tabular}

factors: larger size of cultivated cotton fields, use of higher total quantity of insecticides per household, longer duration of exposure to chemical spraying of the bigger cotton fields. Given the inadequate use of protecttive clothing by pesticide applicators, the odds are that the extracted residues would be absorbed into the skin of the applicators. The occurrence of pesticide drifts is high in the study area because some farmers prefer to spray their cotton fields when the wind speed is high [4]. The reason is that they perceive that high wind speed helps to spread the chemicals much more widely to a larger field area and thus contribute to reduce the quantity (and cost) of pesticides that they needed to apply. The results above showed that pesticide applicators in Korhogo are more exposed to pesticides but the number of health symptoms that they reported is lower than in the Katiola site. The possible explanations for these results are presented in details in section 5 .

\section{Discussions}

\subsection{Cases of Pesticide-Related Health Symptoms}

Farmers in Korhogo site use higher quantities of pesticides and are exposed to chemical spraying for longer period (as they cultivated much bigger cotton fields than their counterparts in Katiola. However, contrary to theoretical expectation, farmers in Korhogo reported a lower number and range of health symptoms. Symptoms were reported in $8 \%$ of the times that farmers in Korhogo applied pesticides in contrast with $37 \%$ in Katiola. In addition, for the health symptoms that were reported by farmers, only in $2 \%$ (1.5\% in Korhogo in contrast with $2.4 \%$ in Katiola) did farmers visit health centres to seek medical assistance. The results also show that the longer the period that farmers have been spraying pesticides, the lower the proportion of the self reported health symptoms that they present to health centres for medical assistance. A number of reasons may explain the attitude 
of farmers regarding pesticide-related health symptoms and visits to health centres to seek medical assistance. The first possible reason is that over time, farmers have been well trained and acquired sufficient skills to handle pesticides and to minimize exposure to the chemicals. Second, due to the longer period in which farmers in Korhogo have been spraying pesticides, they may have developed home grown methods to treat the symptoms on their own (especially the one that are not very severe) and hence, did not visit formal health centres. Third, the proportionately low visits to formal health centres may be a reflection of the non availability of formal health centres within easy reach of farmers, given the general dearth of health facilities in most parts of the rural areas of Côte d'Ivoire. Fourth, farmers have become accustomed to the occurrence of human health hazards of pesticides over a long time and have accepted them as part of the necessary cost of doing farm business, rather than regarding the problems as extra ordinary phenomenon. As one of the farmers in Korhogo site puts it; ' $a$ child who goes to fetch water in the stream should not expect that his clothes will remain dry when he returns to the village'. Fifth, the high cost of medical consultation is unaffordable to many smallholder households and, they were unprepared or unable to pay the high costs (relative to home grown methods) associated with visits to formal medical centres. Irrespective of the reasons for the low proportion of cases for which formal medical assistance was sought by pesticide applicators, these results suggest that the official records of pesticide-related symptoms and pesticide poisoning are most likely under-estimated in Côte d'Ivoire.

Studies from other parts of the world reported similar results showing that the proportion of those who seek medical care is much lower than those who reported acute symptoms from pesticide exposure indicating that official data on pesticide poisoning is seriously underestimated [9,12,21,22]. This is so as only the health symptom cases that are formally reported in health centers could be documented. Previous studies in other parts of the world reported similar results where farmers visited health centres in only very small proportion of cases of pesticide-related health symptoms. A study in Indonesia, found that less than $1 \%$ of pesticide applicators went to a health center with symptoms related to pesticides [20]. Based on various studies, estimates show that the officially documented figures of pesticide poisoning in South Africa are about 5\% - 20\% of the true rates [21]. At global level, official documentation of health poisoning cases is estimated at only $17 \%$ for developing countries [22]. Among cotton farmers in Zimbabwe, only a very small proportion of the health symptoms associated with pesticides were formally reported in health centres either because farmers treated the symptoms as minor problem that do not necessitate medical attention or they rely on home grown treatments [23]. In general, the official documentation of (unintentional) pesticide poisoning cases is linked to the level of economic development of the country, i.e. poorer countries tend to have lower documentation ratios and vice versa. One of the problems posed by under-reporting of pesticide related health problems is that it does not allow policy makers to fully appreciate the extent of unintentional pesticide poisoning and to formulate appropriate policy interventions.

\subsection{Exposure to Pesticides and Applicators' Response to Health Symptoms}

The results of the laboratory residue analysis in this study reveal that applicators in Korhogo site (where pesticides have been used for a longer period of time) faced greater level of exposure to pesticides than Katiola site, but contrary to expectation, the willingness to invest on pesticide-related health expenses is lower in Korhogo site. The results do show that applicators in Korhogo site were not more careful to avoid risks of exposure than their counterparts in Katiola. Rather, there are indications that as the number of years of experience with pesticide spraying increases, pesticide applicators tend to think less of the pesticide-related health symptoms as special problems and so it is not perceived as a 'cost' to them. Over time, applicators perceive health symptoms as 'normal occupational hazards' that should be expected with applying pesticides. This raises the threshold of pain, duration and severity that must be associated with a symptom before it is perceived as "beyond normal" and qualified for special mention and requiring special health care. A study in Asia reported that pesticide applicators tend to accept a certain level of illness as part of the work of farming [20]. In a similar study in Nepal, it was reported that due to the perceived low cost of pesticide-related health costs in comparison to farm production costs, farmers do not take much cognizance of health costs when making farm production decisions to use or not use pesticides [3].

A number of efforts have been made to minimize pesticide-related health problems including changing from more toxic chemicals to less toxic ones (e.g. from organochlorines and organophosphates pesticides to pyrethroids), and featuring pictograms on pesticide labels to communicate risk information of the chemicals to users $[4,5]$. While these efforts have helped in some cases, increases in the quantity of pesticides and exposure to the chemicals continue to fuel concerns about human health problems associated with pesticides. 


\section{Conclusions and Policy Implication}

We conclude that exposure to pesticides and occurrence of ill health symptoms is evident in agricultural households in the cotton growing areas of Cote d'Ivoire. If human health implications of pesticides are taken in cognizance, the cost of using pesticides will increase. Disregarding human health costs of pesticides in economic and policy analysis will result in upward biased estimates of the economic optimum of use of the chemicals. Therefore, it is crucial to understand the linkage between pesticides and the cost of human health arising from their use especially in developing countries where regulations are poorly implemented and farmers' knowledge of safe handling procedures is inadequate. Although precautionary measures against exposure to pesticides are being promoted, occupational poisoning from pesticides still occurs in rural households and it constitutes a major concern in agricultural development planning.

Cotton farmers in Cote d'Ivoire recognize pesticides as one of the important causes of ill health, but over the years they have accepted some of the symptoms as a norm and integral part of pesticide-spraying operation. There is a high likelihood that households in the study area under-estimated pesticide-related health costs in making farm production decisions due to information gap, and the wrong perception about the symptoms. The level of awareness and knowledge of households should be improved to reduce the risks posed from pesticide use to agricultural households. A complementary approach is to actively promote pest management options (e.g. Integrated Pest Management) which minimize the quantity of chemicals used and exposure to occupational hazards among farm households.

There are gaps in documentation of pesticide poisoning as only a very low proportion of cases of health symptoms mentioned by past applicators (2\%) are reported in formal health centres. A mechanism to facilitate formal documentation of pesticide poisoning cases should be put in place. One approach to achieve this is to use economic tool in pesticide policy-making process offering incentives such as free medical assistance to all victims of pesticide poisoning cases in health clinics. Reliable monitoring, assessment and reporting procedures are necessary to formulate appropriate policies and regulations to minimize exposure to pesticides.

\section{ACKNOWLEDGEMENTS}

The authors thank the University of Hannover Germany for the financial assistance provided to the principal author during the field study and, to the cotton farmers who collaborated with us in the study for sharing their time with us. The field data collection and language translation support provided by the study's research assistants-Fofana Aly, Benoït Kouadio, Bakayoko Tiehoulé, Fulbert Kouadio and Fozana Diarassouba—are gratefully acknowledged.

\section{REFERENCES}

[1] Dawson, A.H., Eddleston, M., Senarathna, L., Mohamed, M., Gawarammana, I., Bowe, S.J., Manuweera, G. and Buckley, N.A. (2010) Acute human lethal toxicity of agricultural pesticides: A prospective cohort study. PLOS Medicine, 7, 1-10. doi:10.1371/journal.pmed.1000357

[2] Pimentel, D. (2005) Environmental and economic costs of the application of pesticides primarily in the United States. Environment, Development and Sustainability, 7, 229-252. doi:10.1007/s10668-005-7314-2

[3] Atreya, K. (2008) Health costs from short-term exposure to pesticides in Nepal. Social Science \& Medicine, 67, 511-519. doi:10.1016/j.socscimed.2008.04.005

[4] Ajayi, O.C. and Akinnifesi, F.K. (2007) Farmers' understanding of pesticide safety labels and field spraying practices: case study of cotton farmers in northern Côte d'Ivoire. Scientific Research and Essays, 2, 204-210.

[5] Rother, H.-A. (2008) South African farm workers' interpretation of risk assessment data expressed as pictograms on pesticide labels. Environmental Research, 108, 419427. doi:10.1016/j.envres.2008.07.005

[6] Kishimba, M.A., Henry, L., Mwevura, H., Mmochi, A.J., Mihale, M. and Hellar, H. (2004) The status of pesticide pollution in Tanzania, Talanta, 64, 48-53. doi:10.1016/j.talanta.2003.11.047

[7] Sereda, B.L. and Meinhardt, H.R. (2005) Contamination of the water environment in malaria endemic areas of KwaZulu-Natal, South Africa by agricultural insecticides. Bulletin of Environmental Contamination and Toxicology, 75, 539-537.

[8] Ajayi, O.C. (2005) User costs, biological capital and the productivity of pesticides in sub-Saharan Africa. International Journal of Agricultural Sustainability, 33, 154-166. doi:10.1080/14735903.2005.9684753

[9] Corriols, M., Marin, J., Berroteran, J., Lozano, L.M. and Lundber, I. (2009) Incidence of acute pesticide poisonings in Nicaragua: a public health concern. Occupational \& Environmental Medicine, 66, 205-210. doi:10.1136/oem.2008.040840

[10] Pingali, P.L., Marquez, C.B. and Palis, F.G. (1994) Pesticides and Philippine farmers' health-A medical and economic analysis of impact. American Journal of Agricultural Economics, 76, 587-592. doi:10.2307/1243669

[11] Antle, J.M., Cole, D.C. and Crissman, C.C. (1998) Further evidence on pesticides, productivity and farmer health: Potato production in Ecuador, Agricultural Economics Journal, 18, 199-207. doi:10.1016/S0169-5150(97)00036-4

[12] Crissman, C.C., Cole, D.C. and Carpio, F. (1994) Pesticide use and farm worker health in Ecuadorian potato production. American Journal of Agricultural Economics, 76, 593-597. doi:10.2307/1243670

[13] Ohayo-Mitoko, G.J.A., Kromhout, H., Simwa, J.M., Boleij, J.S.M. and Heederik, D. (2000) Self reported symptoms and inhibition of cholinesterase in Kenya. Occupa- 
tional \& Environmental Medicine, 57, 195-200. doi:10.1136/oem.57.3.195

[14] Rasoul, G.A.M., Salem, M.E.A, Mechael, .A.A, Hendy, O.M., Rohlman, D.S. and Ismail, A.A. (2008) Effects of occupational pesticide exposure on children applying pesticides. Neurotoxicology, 29, 833-838. doi:10.1016/j.neuro.2008.06.009

[15] Balme, K.H., Roberts, J.C., Glasstone, M., Curling, L., Rother, H.-A., London, L., Zar, H. and Mann, M.D. (2010) Pesticide poisonings at a tertiary children's hospital in South Africa: An increasing problem. Clinical Toxicology, 48, 928-934. doi:10.3109/15563650.2010.534482

[16] Garming, H. and Waibel, H. (2009) Pesticides and farmer health in Nicaragua: A willingness-to-pay approach to evaluation. The European Journal of Health Economics, 10, 125-133. doi:10.1007/s10198-008-0110-9

[17] Ajayi, O.C., Akinnifesi, F.K., Sileshi, G. and Ajayi, A,O. (2009) Agricultural policies and the emergence of cotton as the dominant crop in northern Côte d'Ivoire: historical overview and current outlook. Natural Resources Forum, 33, 111-122. doi:10.1111/j.1477-8947.2009.01215.x

[18] Fleischer, G., Andoli, V., Coulibaly, M. and Randolph, T.
(1998) Analyse socio-économique de la filière des pesticides en Côte d'Ivoire. Pesticide Policy Project, Publication Series no 6, University of Hannover, Germany.

[19] Waibel, H. (1994) Towards an economic framework of pesticide policy studies. In: Agne, S., Fleischer, G. and Waibel, H. Eds., Proceedings of the Goettingen Workshop on Pesticide Policies, University of Goettingen, Lower Saxony.

[20] Kishi, M., Hirschon, N., Djajadisastra, M., Satterlee, L.N., Strowman, S. and Dilts, R. (1995) Relationship of pesticide spraying to signs and symptoms in Indonesian farmers Scandinavian Journal of Work \& Environmental Health, 21, 124-133.

[21] London, L. and Rother, A. (1998) Pesticides in occupational health: implications of policy reform. Occupational Health Southern Africa, 4, 30-35.

[22] WHO, (1990) Public health impacts of pesticides used in agriculture, World Health Organization, Geneva.

[23] Maumbe, B.M. and Swinton, S.M. (2003) Hidden health costs of pesticide use in Zimbabwe's smallholder cotton growers. Social Science \& Medicine, 57, 1559-1571. doi:10.1016/S0277-9536(03)00016-9 